\title{
Factors associated to serum paraoxonase 1 activity in patients with cardiovascular disease
}

1 Faculdade de Nutrição, Universidade Federal de Pelotas, Pelotas, RS, Brasil ${ }^{2}$ Instituto de Pesquisa - Hospital do Coração (IP - HCor), São Paulo, SP, Brasil

${ }^{3}$ Faculdade de Medicina, Universidade Federal de Pelotas, Pelotas, RS, Brasil
Correspondence to: Aline Longo

Rua Gomes Carneiro, 1 , sala 242

96010-610 - Pelotas, RS, Brasil alinemlongo@hotmail.com

Received on Aug/22/2020 Accepted on Jan/26/2021

DOI: 10.20945/2359-3997000000354

\author{
Aline Longo ${ }^{1}$ \\ https://orcid.org/0000-0002-6600-8975 \\ Gabriel Barreto Veiga' \\ https://orcid.org/0000-0003-3429-4839 \\ Maria Isabel Schiavon Cousen ${ }^{1}$ \\ https://orcid.org/0000-0002-4241-6392 \\ Caroline Karpinski ${ }^{1}$ \\ https://orcid.org/0000-0002-5618-7367 \\ Augusto Schneider ${ }^{1}$ \\ https://orcid.org/0000-0002-3410-2860 \\ Bernardete Weber ${ }^{2}$ \\ https://orcid.org/0000-0003-1912-652X \\ Eduardo Gehling Bertoldi ${ }^{3}$ \\ https://orcid.org/0000-0001-7290-0348 \\ Lucia Rota Borges ${ }^{1}$ \\ https://orcid.org/0000-0001-8978-4048 \\ Renata Torres Abib Bertacco' \\ https://orcid.org/0000-0003-4793-0566
}

\begin{abstract}
Objective: Paraoxonase 1 (PON1) is an enzyme that has antioxidant potential, which confers a protective effect against the atherosclerotic process. However, studies associating genetics, dietary patterns and PON1 activity in individuals with cardiovascular disease (CVD) are scarce. Thus, the aim of the current study was to evaluate the influence of dietary factors on serum PON1 in CVD patients. Subjects and methods: Cross-sectional, sub-study of the BALANCE Program Trial. All patients aged 45 years or older and had evidence of established atherosclerotic disease in the preceding 10 years. Body weight, height, waist circumference, blood pressure, lipid profile and fasting glucose were collected. Food intake was assessed with 24 -h dietary recall. Data was analyzed using SAS University Edition and a $P$ value $\leq 0.05$ was considered statistically significant. Sample was divided into three groups, according to the PON1 T(-107)C genotype (CC, CT and TT) and serum PON1 activity (Low, Medium, High). Results: There were no genotype differences for major factors. However, the systolic blood pressure was lower for CT individuals $(p<0.05)$. Intake of cholesterol, saturated fatty acids (SFA) and monounsaturated fatty acids (MUFAS) was higher in patients with lower PON1 activity. Lipid ingestion tended to be higher in patients with lower PON1 activity $(p=0.08)$. In the multivariate logistic regression model, SFA intake $(P=0.03)$, genotype $(P=0.09)$, gender $(P=0.04)$, age $(P=0.07)$ and carbohydrate intake $(\mathrm{P}=0.16)$ contributed the most to the serum $\mathrm{PON} 1$ activity. Conclusion: Based on these findings, nutritional guidance for these patients becomes essential, since dietary components interact with serum PON1 activity more than genotype. Arch Endocrinol Metab. 2021;65(6):676-83
\end{abstract}

Keywords

PON1; atherosclerosis; antioxidants; genetics; diet

\section{INTRODUTION}

$\mathrm{T}$ he paraoxonases $(\mathrm{PON})$ are a group of enzymes (1), encoded by genes on chromosome 7 (2). PONl it is the most studied member of this family, can hydrolyze organophosphate compounds (3) and has antioxidant potential $(4,5)$. PONl is synthesized by the liver and released into the bloodstream associated with high density lipoprotein (HDL) molecules (6,7). PONI has a protective effect against the atherosclerotic process as it inhibits oxidation of low-density lipoproteins (LDL) (8). In this context, more than 160 single nucleotide polymorphisms (SNPs) in the PONl gene are known (9). One of the most significant polymorphisms is located in the promoter region of PONl, known as $\mathrm{C}(-107) \mathrm{T}$ or rs705379, which accounts for $12 \%$ of the total variation in serum PONl activity (10). The 
presence of this SNP affects liver gene expression and serum enzyme activity, and the presence of the $\mathrm{C} / \mathrm{G}$ allele is associated with the twice as high PONl serum activity compared to the presence of the T/A allele (1113). Therefore, clearly demonstrating the important role of genetics in serum PONl activity.

In addition to genetic factors, eating habits and the environment can also affect serum PONl activity (11). Despite this, dietary habits contribute less than genetics to the total serum PONI activity $(10,14)$. Nevertheless, consumption of fatty acids and cholesterol can modulate serum PONl activity $(10,11,15)$. However, while some studies indicate that cholesterol is able to increase the serum PONI activity (10), others have not observed the same association (12). In addition, the literature indicates that the effects of dietary intake on PONl activity are dependent on $\mathrm{PONl}$ genotypes, as diets rich in saturated fatty acids (SFA) decrease serum PONl activity in PONl -107 CC individuals only (11). Moreover, it is known that the serum PONl activity is lower in CVD patients compared to healthy individuals (16).

Despite these evidence, studies associating genetics, dietary patterns and PONl activity in individuals with CVD are scarce. In this context, the aim of the current study was to evaluate the influence of dietary factors on serum PONlactivity in patients with CVD.

\section{SUBJECTS AND METHODS}

\section{Volunteers and ethics}

Volunteers are part of Brazilian Cardioprotective Nutritional Program Trial (BALANCE Program Trial) (17), which was being funded by Hospital do Coração (HCor) as part of the "Hospitais de Excelência a Serviço do SUS (PROADI-SUS) program", in partnership with the Brazilian Ministry of Health. All eligibility criteria were reported on the study protocol (17).

The population considered for this cross-sectional sub-study consisted of 64 volunteers from one collaborating center in Southern Brazil (Pelotas, RS, Brazil). Data collected refer to the 12 months of follow-up of the original study. This sub-study was approved by the local ethics committee (CAAE number 48527415.3.0000.5317) and all participants provided written informed consent prior to inclusion.

All patients were aged 45 years or older and had evidence of established atherosclerosis disease in the preceding 10 years: (a) coronary disease (defined by previous myocardial infarction, stable or unstable angina, history of atherosclerotic stenosis $\geq 70 \%$ of the diameter of any coronary artery on conventional or computed tomographic (CT) coronary angiography, or history of angioplasty, stenting, or coronary artery bypass surgery); (b) previous stroke; (c) peripheral vascular disease (ankle/arm ratio $<0.9$ of systolic blood pressure in either leg at rest, angiography or Doppler demonstrating $>70 \%$ stenosis in a cardiac artery, intermittent claudication, vascular surgery for atherosclerotic disease, amputation due to atherosclerotic disease, or aortic aneurysm). The exclusion criteria were: neurocognitive or psychiatric conditions; life expectancy less than 6 months; pregnancy or lactation; liver failure with a history of encephalopathy or anasarca; renal failure with indication for dialysis; congestive heart failure; previous organ transplantation; wheelchair use; or any restrictions to receiving an oral diet.

\section{Sociodemographic, clinical, and behavioral characteristics}

Trained interviewers administered a structured questionnaire comprising questions on clinical characteristics, and blood pressure was obtained by a trained professional. All data were recorded in an electronic case report form (e-CRF).

Body weight and height were measured using a digital calibrated scale with a coupled stadiometer (Filizola ${ }^{\circledR}$ ), with an accuracy of $0.1 \mathrm{~kg}$ and $0.1 \mathrm{~cm}$, respectively. Waist circumference was obtained by inelastic tape measure, at midway between the lowest rib and the iliac crest using an anthropometric tape, with an accuracy of $0.1 \mathrm{~cm}$. Body mass index (BMI) was calculated from weight $(\mathrm{kg})$ divided by squared height $(\mathrm{m})$.

\section{Laboratory measurement}

All volunteers were fasted for at least $12 \mathrm{~h}$ (maximum $14 \mathrm{~h}$ ) before phlebotomy. Total cholesterol, HDL cholesterol, triglycerides and glucose were determined by enzymatic colorimetric dry chemistry method (Ortho-Clinical Diagnostics VITROS 5.1), in venous blood, and LDL cholesterol was estimated using the Friedewald equation (18).

\section{Dietary assessment}

Food intake data were obtained by 24 -h dietary recalls and recorded in the Nutriquanti software 
(São Paulo, SP, Brazil), a Brazilian software which prioritizes the Brazilian composition food tables. A photo album containing images of standardized food portion sizes, specifically prepared by BALANCE Program Trial (17), was used to assist food intake assessment.

\section{Genotyping}

For DNA extraction whole blood samples were used according to a validated protocol (19). To amplify the region where the SNP PONI T(-107) is located, PCR was performed using $10 \mu \mathrm{L}$ of GOTaq ${ }^{\circledR}$ mixture (Promega, Madison, WI, USA), $1 \mu \mathrm{L}(10 \mu \mathrm{M}$ concentration) of primer AGCTAGCTGCGGACCCGGCGGG GAGGaG and $\mathrm{l} \mu \mathrm{L}$ of the reverse primer GGCTGCAGCCCTCACCACAACCC. The lowercase letter in the forward primer indicates a mismatch that introduces a restriction site for the BsrBI enzyme (Thermofischer, Waltham, MA, USA). For the digestion stage, samples were incubated for 2 hours at $37^{\circ} \mathrm{C}$ with $3 \mathrm{U}$ of the BrsBI restriction enzyme. After this, the DNA fragments were separated by gel electrophoresis on 3\% agarose with SYBR Safe (Applied Biosystems, Foster City, CA, USA). The presence of the $\mathrm{C}$ allele was identified by fragments of 28 and 212 base pairs (bp), while the presence of the undigested $\mathrm{T}$ allele, represented by a $240 \mathrm{bp}$ fragment (13).

\section{Serum P0N1 Activity}

PONl arylesterase activity was measured through the formation of phenol, as validated before (20). The working reagent consisted of $20 \mathrm{mM}$ Tris/ $\mathrm{HCl}$ buffer, $\mathrm{pH} 8.0$, including $1 \mathrm{mM} \mathrm{CaCl}$ and $1 \mathrm{mM}$ phenylacetate as a substrate. The samples, before being added to the working reagent, were diluted $1: 3$ in the buffer without phenylacetate and the change in absorbance was recorded for 60 seconds at $270 \mathrm{~nm}$. One unit of arylesterase activity was considered equal to $1 \mathrm{mM}$ of phenol formed per minute and expressed in $\mathrm{U} / \mathrm{mL}$. Blank samples containing only water were used to correct non-enzymatic hydrolysis.

\section{Statistical analysis}

Data was analyzed using SAS University Edition (SAS, Cary, NC, USA). Age and gender were used as co-variates in the analysis. The MIXED procedure was used to test the effect of SNPs on PONI serum activity. Additionally, serum PONl activity was classified in 3 percentiles in High, Medium and Low PONl for comparison of dietary intake among the 3 groups. A stepwise logistic regression procedure was performed to identify independent variables that contributed the most for predicting serum PONl activity. A backward selection technique was used to eliminate covariates that did not contribute to the model. A significance level of 0.20 or above was used to remove covariates from the multivariable model, and a value of 0.15 or less was used to include variables. A P value $\leq 0.05$ was considered statistically significant for an all analysis. Data are presented as mean \pm standard error of mean.

\section{RESULTS}

\section{Effects of the PON1 T(-107)C genotype on serum PON1 activity}

The characteristics of sample are showed in Table 1. There were no genotype differences for major factors. It is important to note that all volunteers in this study were under medical supervision and were properly medicated. Even so, the systolic blood pressure was lower for CT individuals $(\mathrm{p}<0.05)$. The genotype distribution was in Hardy-Weinberg equilibrium $(\mathrm{P}=0.79)$.

Serum PONl activity was not different between PONl T(-107)C genotypes as showed in Figure 1 $(\mathrm{p}>0.05)$.

\section{Effect of dietary intake on PON1 activity}

Regarding dietary factors showed in Table 2, we observed that intake of cholesterol, SFA and monounsaturated fatty acids (MUFAS) was higher in patients with lower PONI activity. Lipid ingestion tended $(\mathrm{p}=0.08)$ to be higher in patients with lower PONl activity.

\section{Combined dietary intake and genetics effects on PON1 activity}

The multivariate logistic regression model was used to identify which variables contributed the most to the serum PONl activity in this group of CVD patients (Table 3). Only SFA intake $(\mathrm{P}=0.03)$, genotype $(\mathrm{P}=0.09)$, gender $(\mathrm{P}=0.04)$, age $(\mathrm{P}=0.07)$, carbohydrate intake $3(\mathrm{P}=0.16)$ remained in the final model in this order, respectively. 


\section{DISCUSSION}

In the current study with subjects in secondary prevention for CVD, we observed that the PONI T(107)C genotype had no effect on serum PONl activity. In these patients, factors that were most associated with serum reduced serum PONl activity were the high intake of cholesterol, SFA and MUFA. SFA, genotype, gender, age and carbohydrate intake were the factors contributing the most for variations in serum PONl activity in the multivariate regression model.
The genotype distribution for the PONl T(-107)C polymorphism observed in our study (18\%:51\%:30\%) was different from the reported for the American (31\%:48\%:20\%) and world population (45\%:39\%:15\%), for the CC, CT and TT genotypes, respectively (21). Additionally, a previous study in the same city showed different allelic proportion (25\%:44\%:32\%), from a sample composed healthy women (12). The lower incidence of the $\mathrm{C}$ allele in our subpopulation can be explained as our population was composed of patients

Table 1. Main parameters according to the PON1 T(-107)C genotype of patients with cardiovascular disease under secondary prevention

\begin{tabular}{|c|c|c|c|c|c|}
\hline & Overall & CC & CT & TT & p value ${ }^{1}$ \\
\hline \multicolumn{6}{|l|}{ General characteristics } \\
\hline Number of patients & 64 & $13(18 \%)$ & $36(51 \%)$ & $15(30 \%)$ & \\
\hline Sex (\% of men) & $43(67.1 \%)$ & $8(61.5 \%)$ & $23(63 \%)$ & $12(80 \%)$ & $>0.05$ \\
\hline Age (years) & $60.5 \pm 1.1$ & $57.3 \pm 2.5$ & $62.5 \pm 1.5$ & $58.2 \pm 2.3$ & 0.11 \\
\hline BMI $\left(\mathrm{kg} / \mathrm{m}^{2}\right)$ & $28.5 \pm 4.3$ & $28.7 \pm 1.2$ & $28.0 \pm 0.7$ & $29.3 \pm 1.1$ & 0.62 \\
\hline Waist circumference (cm) & $98.5 \pm 10.7$ & $96.3 \pm 3.0$ & $98.5 \pm 1.8$ & $100.5 \pm 2.8$ & 0.60 \\
\hline Systolic pressure (mmHg) & $130.5 \pm 20.9$ & $118.3 \pm 5.6$ & $135.7 \pm 3.3$ & $128.0 \pm 5.2$ & 0.03 \\
\hline Diastolic pressure $(\mathrm{mmHg})$ & $79.5 \pm 11.1$ & $76.3 \pm 3.2$ & $81.6 \pm 1.9$ & $78.2 \pm 3.0$ & 0.33 \\
\hline Cholesterol (mg/dL) & $160.4 \pm 40.2$ & $153.9 \pm 11.4$ & $161.6 \pm 6.8$ & $161.8 \pm 10.6$ & 0.83 \\
\hline LDL (mg/dL) & $90.6 \pm 37.9$ & $86.9 \pm 10.7$ & $91.4 \pm 6.4$ & $91.5 \pm 9.9$ & 0.93 \\
\hline HDL (mg/dL) & $37.8 \pm 10.7$ & $39.6 \pm 3.0$ & $38.6 \pm 1.8$ & $32.9 \pm 2.8$ & 0.19 \\
\hline Triacylglycerides (mg/dL) & $160.6 \pm 85.3$ & $147.3 \pm 23.6$ & $161.1 \pm 14.1$ & $176.93 \pm 21.9$ & 0.65 \\
\hline Glucose (mg/dl) & $125.6 \pm 53.2$ & $104.6 \pm 14.5$ & $134.5 \pm 8.7$ & $124.5 \pm 13.5$ & 0.21 \\
\hline Caloric intake (kcal) & $1323.7 \pm 504.5$ & $1604.5 \pm 145.5$ & $1319.2 \pm 87.4$ & $1278.2 \pm 135.4$ & 0.19 \\
\hline Carbohydrates (g) & $172.3 \pm 66.7$ & $183.7 \pm 19.5$ & $178.6 \pm 11.7$ & $160.3 \pm 18.2$ & 0.62 \\
\hline Protein (g) & $63.9 \pm 32.1$ & $79.5 \pm 9.2$ & $61.3 \pm 5.5$ & $61.4 \pm 8.5$ & 0.22 \\
\hline Fat (g) & $43.9 \pm 27.9$ & $63.3 \pm 7.8$ & $41.8 \pm 4.7$ & $45.2 \pm 7.2$ & 0.06 \\
\hline
\end{tabular}

${ }^{1}$ MIXED procedure followed by the Turkey post-hoc test using gender and BMl as co-variates.

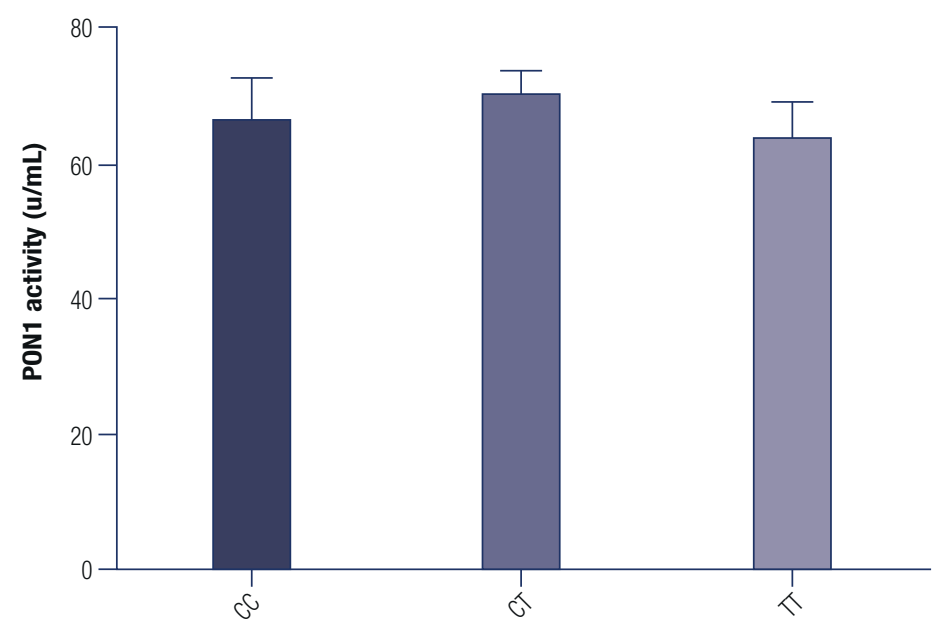

Figure 1. Serum PON1 activity among PON1 T(-107)C genotypes. 
with CVD. The presence of $\mathrm{C}$ allele is associated with higher serum PONl activity and lower CVD risk $(22,23)$, as our sample was formed by CVD subjects, less CC individuals should be expected. Similarly, others found increased incidence of the TT genotype and lower PONl activity in CVD patients (24). The PCR and enzymatic digestion technique are inexpensive and can be easily be applied in a clinical setting. Some reports suggest that the error rate of this technique can range from $0.1-0.5 \%$ (25). Therefore, patient identification can be very precise using this technique.

Interestingly, in the present study we observed no associations between PONl C(-107)T genotypes and serum enzyme activity. Similarly, no differences in PONl activity between genotypes was reported in subjects with diabetes (26). This suggests that other factors besides genetics are important in determining serum $\mathrm{PONl}$ activity in CVD patients. It is important to emphasize that the literature has no studies comparing the effect PONl C(-107)T genotypes on serum PONl activity in CVD patients. Additionally, evidence suggests an important role of inflammation in PONl activity, as PONl activity is reduced in inflammatory diseases, predisposing LDL to oxidation and exacerbating the atheromatous lesion (27).

Literature shows that $12.6 \%$ of serum PON1 variation is predicted by the polymorphism C (-107) T SNP located in the PONI promoter gene, followed by the consumption of cholesterol (10). We observed that genetics had no effect on PONl activity in CVD patients. However, the intake of MUFA, SFA and cholesterol had a marked effect. Consumption of SFA has neutral or lowering effects on HDL concentrations $(28,29)$, thus increasing the risk of CVD $(29)$.

Table 2. Dietary nutrient intake according to serum paraoxonase 1 (PON1) activity

\begin{tabular}{|c|c|c|c|c|}
\hline & Low P0N1 & Medium P0N1 & High PON1 & P Value $^{1}$ \\
\hline Energy intake (kcal) & $1506.9 \pm 112.6$ & $1333.7 \pm 115.2$ & $1255.3 \pm 115.2$ & 0.28 \\
\hline Protein (g) & $74.5 \pm 7.1$ & $58.7 \pm 7.2$ & $61.6 \pm 7.2$ & 0.26 \\
\hline Carbohydrate (g) & $176.4 \pm 15.0$ & $182.3 \pm 15.4$ & $167.3 \pm 15.4$ & 0.78 \\
\hline Total lipids (g) & $57.8 \pm 6.0$ & $43.0 \pm 6.1$ & $39.5 \pm 6.1$ & 0.08 \\
\hline Fiber (mg) & $17.7 \pm 2.6$ & $22.9 \pm 2.7$ & $17.7 \pm 2.7$ & 0.30 \\
\hline 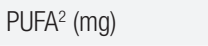 & $10.6 \pm 1.0$ & $9.1 \pm 1.1$ & $8.8 \pm 1.1$ & 0.43 \\
\hline $\mathrm{MUFA}^{3}(\mathrm{mg})$ & $17.4 \pm 1.7$ & $12.0 \pm 1.7$ & $11.9 \pm 1.7$ & 0.04 \\
\hline $\mathrm{SFA}^{4}(\mathrm{mg})$ & $20.3 \pm 2.2$ & $13.8 \pm 2.2$ & $13.0 \pm 2.2$ & 0.05 \\
\hline Cholesterol (mg) & $263.3 \pm 31.8$ & $145.2 \pm 33.4$ & $193.0 \pm 33.4$ & 0.04 \\
\hline Trans fat (mg) & $0.0 \pm 0.0$ & $0.0 \pm 0.0$ & $0.0 \pm 0.0$ & 0.49 \\
\hline Sodium (mg) & $2938.9 \pm 257.2$ & $2764.7 \pm 263.3$ & $2323.6 \pm 263.3$ & 0.23 \\
\hline Calcium (mg) & $525.4 \pm 82.7$ & $468.7 \pm 84.6$ & $479.0 \pm 84.6$ & 0.87 \\
\hline Iron (mg) & $8.5 \pm 0.7$ & $6.8 \pm 0.7$ & $6.4 \pm 0.7$ & 0.30 \\
\hline Potassium (mg) & $2209.1 \pm 183.3$ & $1757.0 \pm 187.6$ & $1889.8 \pm 187.6$ & 0.21 \\
\hline Magnesium (mg) & $161.3 \pm 15.7$ & $173.8 \pm 16.0$ & $161.3 \pm 16.0$ & 0.47 \\
\hline Phosphor (mg) & $935.5 \pm 72.7$ & $734.4 \pm 74.5$ & $777.7 \pm 74.5$ & 0.13 \\
\hline Copper (ug) & $3.5 \pm 2.3$ & $0.9 \pm 2.4$ & $4.9 \pm 2.4$ & 0.50 \\
\hline Zinc (mg) & $10.5 \pm 1.1$ & $8.3 \pm 1.2$ & $8.2 \pm 1.2$ & 0.30 \\
\hline
\end{tabular}

${ }^{1}$ MIXED procedure followed by the Turkey post-hoc test using gender and BMI as co-variates. ${ }^{2}$ PUFA (Polyunsaturated Fatty Acids). ${ }^{3}$ MUFA (Monounsaturated Fatty Acids). ${ }^{4}$ SFA (Saturated Fatty Acids).

Table 3. Multivariate logistic regression analysis for dietary intake and genetics effects on serum PON1 activity

\begin{tabular}{|c|c|c|c|c|c|}
\hline \multirow{2}{*}{$\begin{array}{l}\text { Effect } \\
S F A^{3}\end{array}$} & \multirow{2}{*}{  } & \multirow{2}{*}{$\begin{array}{c}\text { Score }^{2} \\
4.5\end{array}$} & \multirow{2}{*}{$\begin{array}{c}\text { P Value } \\
0.03\end{array}$} & \multicolumn{2}{|c|}{ Overall model assessment } \\
\hline & & & & Concordant, \% & 76.9 \\
\hline Genotype & 2 & 4.6 & 0.09 & Discordant, \% & 22.9 \\
\hline Sex & 3 & 4.1 & 0.04 & Tied, \% & 0.2 \\
\hline Age & 4 & 3.2 & 0.07 & & \\
\hline Cho intake ${ }^{4}$ & 5 & 1.9 & 0.16 & & \\
\hline
\end{tabular}

${ }^{1}$ Order for inclusion of the parameter in the model. ${ }^{2}$ Chi-square score. ${ }^{3}$ Saturated fatty acids. ${ }^{4}$ Carbohydrate intake. 
Likewise, serum PONl activity is also reduced by the consumption of fats in diet (30-32), since PONl and HDL levels are correlated (5). Thus, our study in CVD patients is in line with previous studies in the healthy population, where the consumption of these dietary factors predisposes to a reduction in serum PONl and an increased risk of CVD. The total consumption of lipids in our study tended to be higher in individuals with lower PONl activity. This variable may have been influenced by the low-fat consumption adopted by our sample, which was composed of people who have already suffered from CVD.

Our results indicate a negative relationship between higher cholesterol consumption and PONl activity, similarly to that found in mice susceptible to atherosclerosis (32). Cholesterol consumption contributes to about $5.5 \%$ of variation in $\mathrm{PONl}$ activity levels (10). These findings diverge from two other studies that show a positive relationship between cholesterol consumption and increased enzyme activity, one seen in baboons (33) and the other in humans (10). Although paradoxical, since PONl activity is protective, while dietary cholesterol intake is atherogenic, dietary cholesterol is positively and significantly associated with PONl activity and HDL concentration, thus indicating that the increase in PONl activity exceeds any increase in HDL (10). Usually cholesterol-rich diets are also abundant in saturated and trans-fat, and even low in PUFAS, which could justify our findings of lower PONl activity with higher cholesterol consumption.

Our data indicate that the higher intake of SFA, prevalent in the Western diet (34), is negatively associated to serum PONl activity. Although other authors have not found a direct association between SFA and cholesterol consumption with enzymatic reduction of $\mathrm{PONl}(35)$. It is known that the high and prolonged consumption of SFA is associated with an increased risk of CVD (36) for reducing HDL levels (29) to which PONl is associated (5), corroborating with our findings. Furthermore, a study that evaluated the interaction of the genotype with fat consumption demonstrated that women of the PON-107 CC genotype, ingesting more than $40 \%$ of fat from SFA had a significant reduction in serum PONl activity, although no difference was observed in women of the CT and TT genotypes (11).

Paradoxically to what was expected regarding the effects of MUFAS, our findings indicated a negative relationship between high consumption of MUFA and PONI activity. One study evaluated that the high intake of oleic acid by men homozygous for the R allele in the PON1-192 polymorphism resulted in increased HDL levels and PONI activity (37). The consumption of olive oil, rich in oleic acid, after heat treatment by diabetic patients has demonstrated effectiveness in raising postprandial PONl activity, most notably in women (38). Therefore, in our sample group of CVD patients, in which the greater consumption of MUFAS also coincided with that of other fats can explain these differences. As our patients did not follow a Mediterranean style diet, rich in MUFAs along antioxidant compounds, which can modulate PONl activity $(39,40)$. In our study with CVD patients, the intake of PUFAs did not seem to be associated with PONl activity.

The multiple logistic regression analysis showed that the most important factors associated to serum PONl activity were SFA intake, genotype, gender, age and carbohydrate intake, in this order respectively. Although some individual effects of genotype, gender and age were not observed, their combined interaction can significantly affect PONl activity. Regarding gender differences, serum PONl activity in females is higher than in males (4l), as estradiol has been shown to enhance PONl activity independent of liver synthesis (42). Despite this, our previous study showed no difference between pre and post-menopausal women regarding serum PONl activity (12). The occurrence of CVD in premenopausal women is lower than in men of the same age, however, it increases in postmenopausal women to levels comparable to men (43), due atherosclerotic plaque formation being slower in women (44). Furthermore, the multiple regression model indicated that carbohydrate intake had a small contribution to serum PONl activity in these CVD patients. One study found association between serum PONl activity and carbohydrate intake, but just in subjects with cardiovascular risk factors, with no association in CVD group (45). Total carbohydrate intake was inversely associated with HDL cholesterol concentrations (44), which could in turn affect negatively $\mathrm{PONl}$ activity as we observed in this work.

There are some limitations in our study. Recall was performed once, which may not reflect habitual consumption and presents a memory bias and also the low number of individual for a genotype study. Nevertheless, this study showed, for the first time, the 
consumption of SFA, MUFA and carbohydrate, which can be modified through nutritional intervention, associated with serum PONl activity, an important enzyme involved in cardiovascular health.

In this sample of patients with CVD, high intake of cholesterol, SFA and MUFA were associated with reduced serum PONl activity, while PONl T(1-07)C genotype had no effect. The multiple logistic regression model indicated that SFA, genotype, gender, age and carbohydrate intake were the factors contributing the most for variations in serum PONl activity. Based on these findings, nutritional guidance for these patients becomes essential, since dietary components interact with serum PONl activity more than genetic factors.

Acknowledgments: to Coordenação de Aperfeiçoamento de Pessoal de Nivel Superior (CAPES) for a research scholarship and to DICA Br, for all support.

Authors contributions: Aline Longo, Eduardo Gehling Bertoldi, Lúcia Rota Borges and Renata Torres Abib Bertacco designed the study. Aline Longo collected data. Gabriel Barreto Veiga, Maria Isabel Schiavon Cousen, Caroline Karpinski and Augusto Schneider performed the experiments and the statistical analysis. Aline Longo, Gabriel Barreto Veiga, Maria Isabel Schiavon Cousen, Caroline Karpinski, Augusto Schneider, Lúcia Rota Borges and Renata Torres Abib Bertacco wrote the paper. Bernardete Weber is the principal investigator of Brazilian Cardioprotective Nutritional Program Trial and contributed also for this manuscript.

Disclosure: no potential conflict of interest relevant to this article was reported.

\section{REFERENCES}

1. Milnerowicz $\mathrm{H}$, Kowalska K, Socha E. Paraoxonase activity as a marker of exposure to xenobiotics in tobacco smoke. Int $\mathrm{J}$ Toxicol. 2015;34:224-32.

2. Primo-Parmo SL, Sorenson RC, Teiber J, La Du BN. The human serum paraoxonase/arylesterase gene (PON1) is one member of a multigene family. Genomics. 1996;33:498-507.

3. Mazur A. An enzyme in animal tissues capable of hydrolysing the phosphorus-fluorine bond of alkyl fluorophosphates. J Biol Chem. 1946;164:271-89.

4. Meneses MJ, Silvestre R, Sousa-Lima I, Macedo MP. Paraoxonase-1 as a Regulator of Glucose and Lipid Homeostasis: Impact on the Onset and Progression of Metabolic Disorders. Int J Mol Sci. 2019;20:4049.

5. Mackness MI, Arrol S, Durrington PN. Paraoxonase prevents accumulation of lipoperoxides in low-density lipoprotein. FEBS Lett. 1991;286:152-4.

6. James RW, Brulhart-Meynet M-C, Singh AK, Riederer B, Seidler $U$, Out $R$, et al. The scavenger receptor class $B$, type I is a primary determinant of paraoxonase-1 association with high-density lipoproteins. ArteriosclerThromb Vasc Biol. 2010;30:2121-7.

7. Mackness MI, Arrol S, Durrington PN. Paraoxonase prevents accumulation of lipoperoxides in low-density lipoprotein. FEBS letters. 1991;286:152-4.
8. Hasselwander O, McEneny J, McMaster D, Fogarty DG, Nicholls DP, Maxwell AP, et al. HDL composition and HDL antioxidant capacity in patients on regular haemodialysis. Atherosclerosis. 1999;143:125-33.

9. Costa LG, Vitalone A, Cole TB, Furlong CE. Modulation of paraoxonase (PON1) activity. Biochem Pharmacol. 2005;69:54150.

10. Kim DS, Burt AA, Ranchalis JE, Richter RJ, Marshall JK, Nakayama KS, et al. Dietary cholesterol increases paraoxonase 1 enzyme activity. J Lipid Res. 2012;53:2450-8.

11. Santos FG, Becker MK, Correa VS, Garcia DN, Vale SC, CrespoRibeiro JA, et al. The effect of the paraoxonase 1 (PON1)T(-107)C polymorphism on serum PON1 activity in women is dependent on fatty acid intake. Nutr Res. 2016;36:9-15.

12. Ritta MC, Baldez AM, Oliveira IO, Garcia DN, Souza PS, Andrade $\mathrm{K}$, et al. Paraoxonase 1 serum activity in women: the effects of menopause, the $\mathrm{C}(-107) \mathrm{T}$ polymorphism and food intake. Arch Endocrinol Metab. 2019;63:272-9.

13. Campo S, Sardo MA, Trimarchi G, Bonaiuto M, Fontana L, Castaldo $M$, et al. Association between serum paraoxonase (PON1) gene promoter T(-107)C polymorphism, PON1 activity and HDL levels in healthy Sicilian octogenarians. Exp Gerontol. 2004;39:1089-94.

14. Kim DS, Maden SK, Burt AA, Ranchalis JE, Furlong CE, Jarvik GP. Dietary fatty acid intake is associated with paraoxonase 1 activity in a cohort-based analysis of 1,548 subjects. Lipids Health Dis. 2013;12:183.

15. Blum S, Aviram M, Ben-Amotz A, LevyY. Effect of a Mediterranean meal on postprandial carotenoids, paraoxonase activity and C-reactive protein levels. Ann Nutr Metab. 2006;50:20-4.

16. Abello D, Sancho E, Camps J, Joven J. Exploring the role of paraoxonases in the pathogenesis of coronary artery disease: a systematic review. Int J Mol Sci. 2014;15:20997-1010.

17. Weber B, Bersch-Ferreira AC, Torreglosa CR, Ross-Fernandes MB, da Silva JT, Galante AP, et al. The Brazilian Cardioprotective Nutritional Program to reduce events and risk factors in secondary prevention for cardiovascular disease: study protocol (The BALANCE Program Trial). Am Heart J. 2016;171:73-81 e1-2.

18. Friedewald WT, Levy RI, Fredrickson DS. Estimation of the concentration of low-density lipoprotein cholesterol in plasma, without use of the preparative ultracentrifuge. Clin Chem. 1972;18:499-502.

19. Kanai N, Fujii T, Saito K, Tokoyama T. Rapid and simple method for preparation of genomic DNA from easily obtainable clotted blood. J Clin Pathol. 1994;47:1043-4.

20. Browne RW, Koury ST, Marion S, Wilding G, Muti P, Trevisan M. Accuracy and biological variation of human serum paraoxonase 1 activity and polymorphism (Q192R) by kinetic enzyme assay. Clin Chem. 2007;53:310-7.

21. Clarke L, Fairley S, Zheng-Bradley X, Streeter I, Perry E, Lowy $E$, et al. The international Genome sample resource (IGSR): A worldwide collection of genome variation incorporating the 1000 Genomes Project data. Nucleic Acids Res. 2017;45:D854-D9.

22. Decharatchakul N, Settasatian C, Settasatian N, Komanasin $\mathrm{N}$, Kukongviriyapan $U$, Intharapetch $P$, et al. Association of combined genetic variations in SOD3, GPX3, PON1, and GSTT1 with hypertension and severity of coronary artery disease. Heart Vessels. 2020 Jul;35(7):918-29.

23. Rojas-Garcia AE, Solis-Heredia MJ, Pina-Guzman B, Vega L, Lopez-Carrillo L, Quintanilla-Vega B. Genetic polymorphisms and activity of PON1 in a Mexican population. Toxicol Appl Pharmacol. 2005;205:282-9.

24. James RW, Leviev I, Ruiz J, Passa P, Froguel P, Garin MC. Promoter polymorphism $\mathrm{T}(-107) \mathrm{C}$ of the paraoxonase PON1 gene is a risk factor for coronary heart disease in type 2 diabetic patients. Diabetes. 2000;49:1390-3. 
25. Hubacek JA, Pikhart H, Peasey A, Kubinova R, Bobak M. Nobody Is Perfect: Comparison of the Accuracy of PCR-RFLP and KASPTM Method for Genotyping. ADH1B and FTO Polymorphisms as Examples. Folia Biologica (Praha). 2015;61:4.

26. Flekac M, Skrha J, Zidkova K, Lacinova Z, Hilgertova J. Paraoxonase 1 gene polymorphisms and enzyme activities in diabetes mellitus. Physiol Res. 2008;57:717-26.

27. Feingold KR, Memon RA, Moser AH, Grunfeld C. Paraoxonase activity in the serum and hepatic mRNA levels decrease during the acute phase response. Atherosclerosis. 1998;139:307-15.

28. Sundram K, Ismail A, Hayes KC, Jeyamalar R, Pathmanathan R. Trans (elaidic) fatty acids adversely affect the lipoprotein profile relative to specific saturated fatty acids in humans. J Nutr. 1997;127:514S-20S.

29. Hunter JE, Zhang J, Kris-Etherton PM. Cardiovascular disease risk of dietary stearic acid compared with trans, other saturated, and unsaturated fatty acids: a systematic review. Am J Clin Nutr. 2010;91:46-63.

30. de Roos NM, Schouten EG, Scheek LM, van Tol A, Katan MB. Replacement of dietary saturated fat with trans fat reduces serum paraoxonase activity in healthy men and women. Metabolism. 2002;51:1534-7.

31. Blum S, Aviram M, Ben-Amotz A, LevyY. Effect of a Mediterranean Meal on Postprandial Carotenoids, Paraoxonase Activity and C-Reactive Protein Levels. Ann Nutr Metab. 2006;50:20-4.

32. Shih DM, Gu L, Hama S, Xia YR, Navab M, Fogelman AM, et al. Genetic-dietary regulation of serum paraoxonase expression and its role in atherogenesis in a mouse model. J Clin Invest. 1996;97:1630-9.

33. Rainwater DL, Mahaney MC, Wang XL, Rogers J, Cox LA, Vandeberg JL. Determinants of variation in serum paraoxonase enzyme activity in baboons. J Lipid Res. 2005;46:1450-6.

34. Arbonés-Mainar JM, Navarro MA, Carnicer R, Guillén N, Surra JC, Acín S, et al. Accelerated atherosclerosis in apolipoprotein E-deficient mice fed Western diets containing palm oil compared with extra virgin olive oils: a role for small, dense high-density lipoproteins. Atherosclerosis. 2007;194:372-82.
35. Lixandru D, Mohora M, Coman A, Stoian I, van Gils C, Aerts P, et al. Diet and paraoxonase 1 enzymatic activity in diabetic foot patients from Romania and Belgium: favorable association of high flavonoid dietary intake with arylesterase activity. Ann Nutr Metab. 2010;56:294-301.

36. Thijssen MA, Mensink RP. Fatty acids and atherosclerotic risk. Handb Exp Pharmacol. 2005:165-94.

37. Tomás $M$, Sentí $M$, Elosua $R$, Vila J, Sala J, Masià $R$, et al. Interaction between the Gln-Arg 192 variants of the paraoxonase gene and oleic acid intake as a determinant of high-density lipoprotein cholesterol and paraoxonase activity. Eur J Pharmacol. 2001;432:121-8.

38. Wallace AJ, Sutherland WH, Mann JI, Williams SM. The effect of meals rich in thermally stressed olive and safflower oils on postprandial serum paraoxonase activity in patients with diabetes. Eur J Clin Nutr. 2001;55:951-8.

39. Lou-Bonafonte JM, Gabas-Rivera C, Navarro MA, Osada J. PON1 and Mediterranean Diet. Nutrients. 2015;7:4068-92.

40. Durrington PN, Mackness B, Mackness MI. The hunt for nutritional and pharmacological modulators of paraoxonase. Arterioscler Thromb Vasc Biol. 2002;22:1248-50.

41. Costa LG, Vitalone A, Cole TB, Furlong CE. Modulation of paraoxonase (PON1) activity. Biochem Pharmacol. 2005;69:541-50.

42. Ahmad S, Scott JE. Estradiol enhances cell-associated paraoxonase 1 (PON1) activity in vitro without altering PON1 expression. Biochem Biophys Res Commun. 2010;397:441-6.

43. Wellons M, Ouyang P, Schreiner PJ, Herrington DM, Vaidya D. Early menopause predicts future coronary heart disease and stroke: the Multi-Ethnic Study of Atherosclerosis. Menopause. 2012;19:1081-7.

44. Sutton-Tyrrell K, Lassila HC, Meilahn E, Bunker C, Matthews KA, Kuller LH. Carotid atherosclerosis in premenopausal and postmenopausal women and its association with risk factors measured after menopause. Stroke. 1998;29:1116-21.

45. Ponce-Ruiz N, Murillo-Gonzalez FE, Rojas-Garcia $A E$, Bernal HernandezYY, Ma-ckness M, Ponce-Gallegos J, et al. Phenotypes and concentration of PON1 in cardi-ovascular disease:The role of nutrient intake. Nutr Metab Cardiovasc Dis. 2020;30:40-8. 